\title{
Solvent extraction followed by ultraviolet detection for investigation of tetramethylthiuram disulfide at soil-water interface
}

\author{
*N. Priyantha; A. Navaratne; C. B. Ekanayake; A. Ratnayake \\ Department of Chemistry, University of Peradeniya, Peradeniya, Sri Lanka \\ Received 29 May 2008; $\quad$ revised 25 June 2008; accepted 18 July 2008; available online 1 September 2008
}

\begin{abstract}
Tetramethylthiuram disulfide is a widely used pesticide and a soil treatment agent in the agricultural sector. Consequently, its detection in the environment and investigation of the distribution between the aqueous and soil phases would be of highly importance. In this study, the detection of tetramethylthiuram disulfide in $\mathrm{CHCl}_{3}$ was successfully achieved through absorbance measurements at 280 $\mathrm{nm}$, which resulted in linear calibration curves. This detection method was extended for the determination of the partition coefficient $\left(\mathrm{K}_{\mathrm{D}}\right)$ of tetramethylthiuram disulfide between $\mathrm{CHCl}_{3}$ and $\mathrm{H}_{2} \mathrm{O}$ phases at ambient temperature. The partition coefficient was subsequently used to determine the apparent partition coefficient $\left(\mathrm{K}_{\mathrm{D}}\right)$ of tetramethylthiuram disulfide between sieved soil of diamater $<2.0 \mathrm{~mm}$ used for agricultural practices and water where by the quantification of tetramethylthiuram disulfide in water after adsorption equilibrium with soil was achieved through a solvent extraction step of tetramethylthiuram disulfide-contaminated water into $\mathrm{CHCl}_{3}$. The $\mathrm{K}_{\mathrm{D}}$ determined for an initial tetramethylthiuram disulfide concentration ranging from $3.00 \mathrm{ppm}$ to $10.00 \mathrm{ppm}$ showed a decreasing trend, which leveled off at high concentrations, indicating the strong irreversible adsorption behavior of tetramethylthiuram disulfide on soil at low concentrations. The proposed detection method would have the potential to determine the extent of adsorption of tetramethylthiuram disulfide in soil or its levels in water when tetramethylthiuram disulfide is introduced to soil systems for agricultural practices.
\end{abstract}

Key words: Pesticides, adsorption, partition coefficient, analytical methods, environmental monitoring

\section{INTRODUCTION}

Tetramethylthiuram disulfide (Thiram) belongs to the dithiocarbamate family of pesticides, which is registered as a general purpose pesticide by the U.S. Environmental Protection Agency (EPA) and classified as toxicity class III. Formulations of thiram are available as dust, flowable or wettable powder, water dispensable granules and water suspensions (Kidd and James, 1991). Thiram is used as a fungicide to protect harvested crops and prevent crop damage in the field, and as a seed protectant to prevent various fungal diseases (Han et al., 2003; Sharma et al., 2003; Bradley et al., 2007). It is also used in rubber industry as an accelerator and a vulcanization agent (Ceresera et al., 2001; Grosicka et al., 2005). It is used by humans in the treatment of scabies and as a bactericide for skin (Ceresera et al., 2001). Ingestion and inhalation of thiram is slightly toxic while dermal adsorption is

凶*Corresponding Author Email: namalpriyantha@pdn.ac.lk Tel.: +94 81 2394445; Fax: +94 812389129 moderately toxic. Thiram breaks down in the human body to give carbon disulfide which causes some damage to the liver. Ecologically it is nontoxic to birds (high $\mathrm{LC}_{50}$ ), but highly toxic to fish as $\mathrm{LC}_{50}$ values for most of the fish species are below $5 \mathrm{ppm}$ (Fernandez et al., 1996). Thiram is slightly soluble in water (30 ppm at $25^{\circ} \mathrm{C}$ ), and consequently, it is immobile in soils high in clay and organic matter content. The half-life of thiram in the soil (15 days) is shorter compared to that of many pesticides (Aulakh et al., 2005).

Thiram, being a toxic substance for aquatic life, should be detected with an acceptable accuracy. Among many methods available for the detection of thiram and related substances, gas chromatography, high performance liquid chromatography, thin layer densitometry, Fourier transform infrared spectroscopy, capillary electrophoresis and voltammetry have been successful for a variety of sample matrices (Procopio et al., 1988; Sharma et al., 2003; Priyantha and 
Weliwegamage, 2005 and 2008). Special reagents have been used in many of these techniques to improve selectivity and/or sensitivity. For instance, thin layer densitometry of copper complexes of dithiocarbamates provides a simple and rapid means of their detection (Onuska, 1974). Extraction of thiram with cyclohexaneethyl acetate followed by HPLC with UV detection allows the detection at $0.1-0.2 \mathrm{ppm}$ level (Ekroth et al., 1998). Detection limits have been further enhanced to 3.8 ppt (parts per trillion) through a postcolumn reaction detector that employs UV photolysls with o-phthalaldehyde-2-mercaptoethanol followed by fluorometric determination (Miles and Moye, 1988). In a different study, conversion of thiram to a selenium dithiocarbamate complex, followed by extraction into chloroform and measuring at $430 \mathrm{~nm}$ is able to detect at ppb levels (Malik and Rao, 1990). Improvement in detection limits has also been achieved by incorporating a solid phase microextraction step (Aulakh et al., 2005).

Sorption equilibrium of a chemical species at the soil/water interface plays a major role in aquatic chemistry and environmental science (Spark et al., 2002; Kang et al., 2002; Boivin et al., 2005; Sheng et al., 2005). When toxic substances, such as pesticides, are involved in such equilibrium, sorption characteristics should be known with high accuracy as the molecules that are not bound to soil particles directly reach the environment which may ultimately cause a strong impact on humans (Fava et al., 2005).

This problem would be alarming if the levels of a pesticide in the environment were greater than the tolerable limits. Consequently, there has been much attention on the adsorption behavior of organic contaminants on natural particles (Rytwo et al., 2002; Schmidt et al., 2004; Tsai and Lai, 2006; Changwen et al., 2006).

Additionally, many model studies for adsorption of organic substances with clay-based materials have been reported (Pu et al., 2003; Akçay, 2004; Kaya and Ören, 2005). Nevertheless, due to inhomogeneity of soil, which results in unpredictable surface reactivity and irreproducible measurements, designing sorption models for pesticides at the soil/water interface has become a challenge despite the information obtained from such processes being of great importance. In the present study, a reliable, economical detection method for thiram present in soil suspensions was employed based on a solvent extraction step followed by ultra- violet (UV) detection. Sorption studies were also conducted for commercially available bentonite clay for comparison. The results were subsequently used for investigation of the validity of adsorption models.

\section{MATERIALS AND METHODS}

\section{Instrumentation}

A UV-Visible scanning spectrophotometer (Shimadzu 160 UV-Visible) was used to record absorption spectra of thiram in both aqueous and $\mathrm{CHCl}_{3}$ media. The optimum wavelength for the detection of thiram was determined, and used throughout the study. The metals present in soil samples were determined using an Atomic Absorption Spectrophotometer (Buck Scientific, Model 200-A).

\section{Materials}

Three agricultural fields representing different geographical areas of Sri Lanka were selected to obtain soil samples. Each sample was collected (August, 2006) from the upper $25 \mathrm{~cm}$. of the surface horizon following removal of surface vegetation. Samples were mixed well, air dried for $24 \mathrm{~h}$. and sieved to remove solid particles of diameter over $2 \mathrm{~mm}$ in order to make the soil matrix homogeneous. Bentonite, a commercial soil used for comparison studies, was purchased from SigmaAldrich.

A commercial sample of thiram [Tetramethylthiuram disulfide, $\left(\mathrm{H}_{3} \mathrm{C}\right)_{2} \mathrm{NCS}_{2} \mathrm{~S}_{2} \mathrm{CN}\left(\mathrm{CH}_{3}\right)_{2}, 80 \%$ w/w] was purchased from the local market. Tetramethylthiuram disulfide (97\%), which was purchased from SigmaAldrich, was recrystallized, melting point (Reported $155.5^{\circ} \mathrm{C}$ ) was checked, and used for the standardization of commercial samples. All solutions were prepared in either distilled water or double distilled $\mathrm{CHCl}_{3}$. Standard solutions of metals ions $(\mathrm{Cu}, \mathrm{Fe}, \mathrm{Zn}, \mathrm{Na}$ and $\mathrm{K}$ ) for atomic absorption measurements were prepared using analytical grade reagents in deionized water. Soil samples were digested using HF and aqua regia for absorption measurements.

\section{Methods}

Optimization of experimental parameters and determination of analytical characteristics are important in accurate detection of any substance. High solubility of thiram in $\mathrm{CHCl}_{3}$ and its immiscibility with water would provide sufficient conditions for the selection of $\mathrm{CHCl}_{3}$ as the solvent of choice. The absorbance of thiram solutions in $\mathrm{CHCl}_{3}$ of 
concentrations varying from 1 to $10 \mathrm{ppm}$ was measured in triplicate at $280 \mathrm{~nm}$, and the corresponding calibration curve was constructed. Aqueous solutions of thiram of the same concentration range as stated above were allowed to reach partition equilibrium with $\mathrm{CHCl}_{3}$, after which, aliquots of the $\mathrm{CHCl}_{3}$ layer were withdrawn and the adsorption of each solution was measured in triplicate at $280 \mathrm{~nm}$. Homogenized soil samples (30 g) and aqueous solutions of thiram $\left(60 \mathrm{~cm}^{3}\right)$ of different concentrations (1 to $10 \mathrm{ppm}$ ) were stirred for $15 \mathrm{~min}$. Three replicate experiments were performed for each concentration. Each sample was allowed to stand for 2 h. to reach equilibrium. An aliquot of $20 \mathrm{~cm}^{3}$ of the supernatant of each solution was withdrawn and shaken with $20 \mathrm{~cm}^{3}$ of chloroform in a separating funnel. The mixture was allowed to separate, after which, the chloroform layer was withdrawn, and its absorbance measured at $280 \mathrm{~nm}$. Thesame procedure was used for bentonite. Calibration curves were used for the determination of the concentration of thiram in the chloroform layer. Average apparent distribution coefficient for each concentration for each soil type and for bentonite was then determined.

\section{RESULTS AND DISCUSSION}

The calibration curve for the direct UV determination of thiram in $\mathrm{CHCl}_{3}$ at $280 \mathrm{~nm}$, constructed using average absorbance values, is shown in Fig. 1. The minimum detection limit (MDL), linear dynamic range (LDR) and sensitivity were $0.170 \mathrm{ppm}, 1 \mathrm{ppm}$ to $10 \mathrm{ppm}$, and 0.086 / ppm, respectively. The linear regression equation and the correlation coefficient of the calibration curve drawn within the LDR are $\mathrm{y}=0.037+0.075$ and $\mathrm{R}^{2}=0.9753$, respectively.The partition coefficient of thiram between $\mathrm{CHCl}_{3}$ and water, determined by measuring the levels of thiram in the $\mathrm{CHCl}_{3}$ phase after partitioning with the aqueous phase containing thiram, resulted in an average value of $5.86 \pm 0.54$ over 15 replicates within the initial concentration range of $1 \mathrm{ppm}$ to $10 \mathrm{ppm}$ in water. The minimum detection limit obtained in this method was comparable to that of the more sophisticated methods such as high performance liquid chromatography that employs sensitive detectors (Fernadez et al., 1996; Ekroth et al., 1998). The simplicity of the detection method developed is an added attraction for quantification of thiram. Other advantages of using $\mathrm{CHCl}_{3}$ as the medium are that aqueous solutions of low

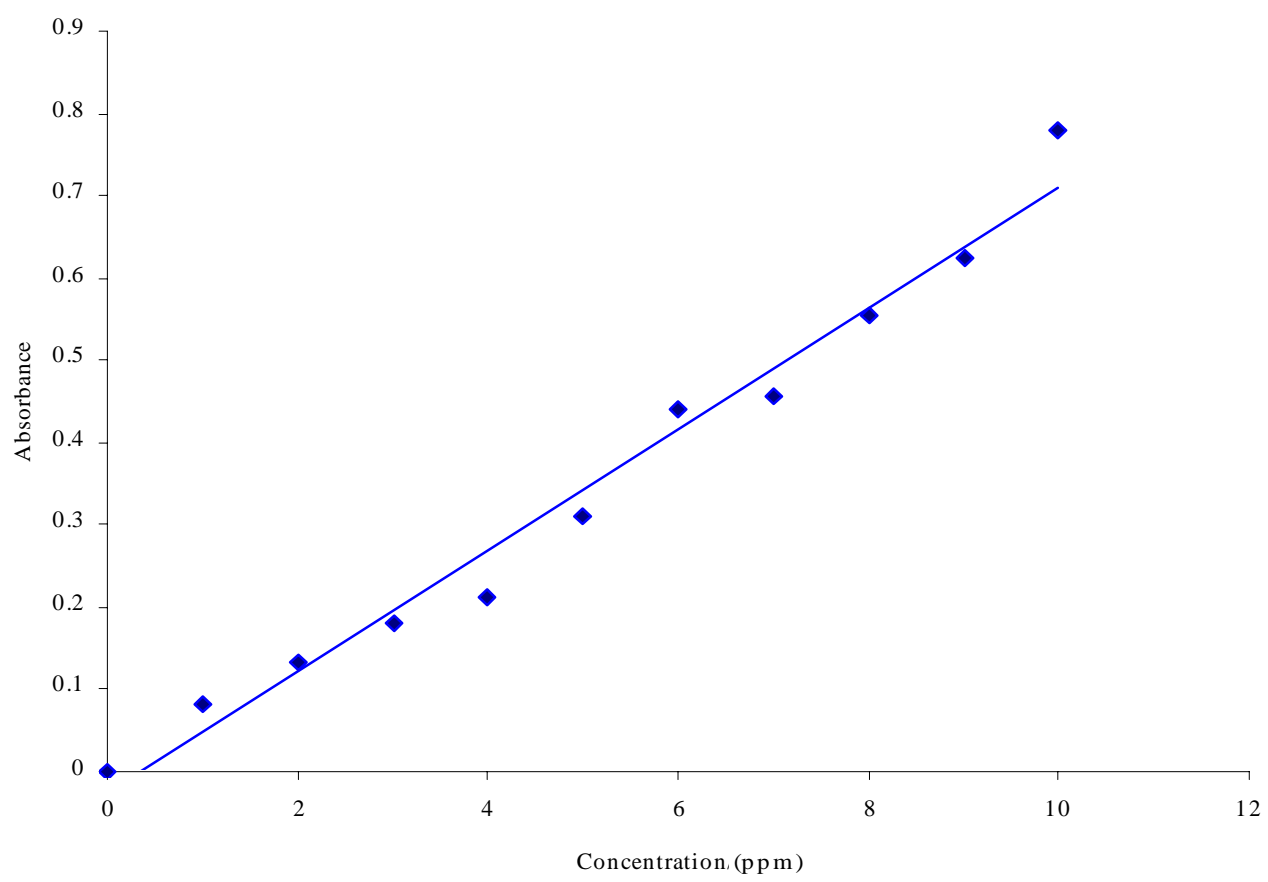

Fig. 1: Calibration curve of the UV detection method of thiram in $\mathrm{CHCl}_{3}$ 


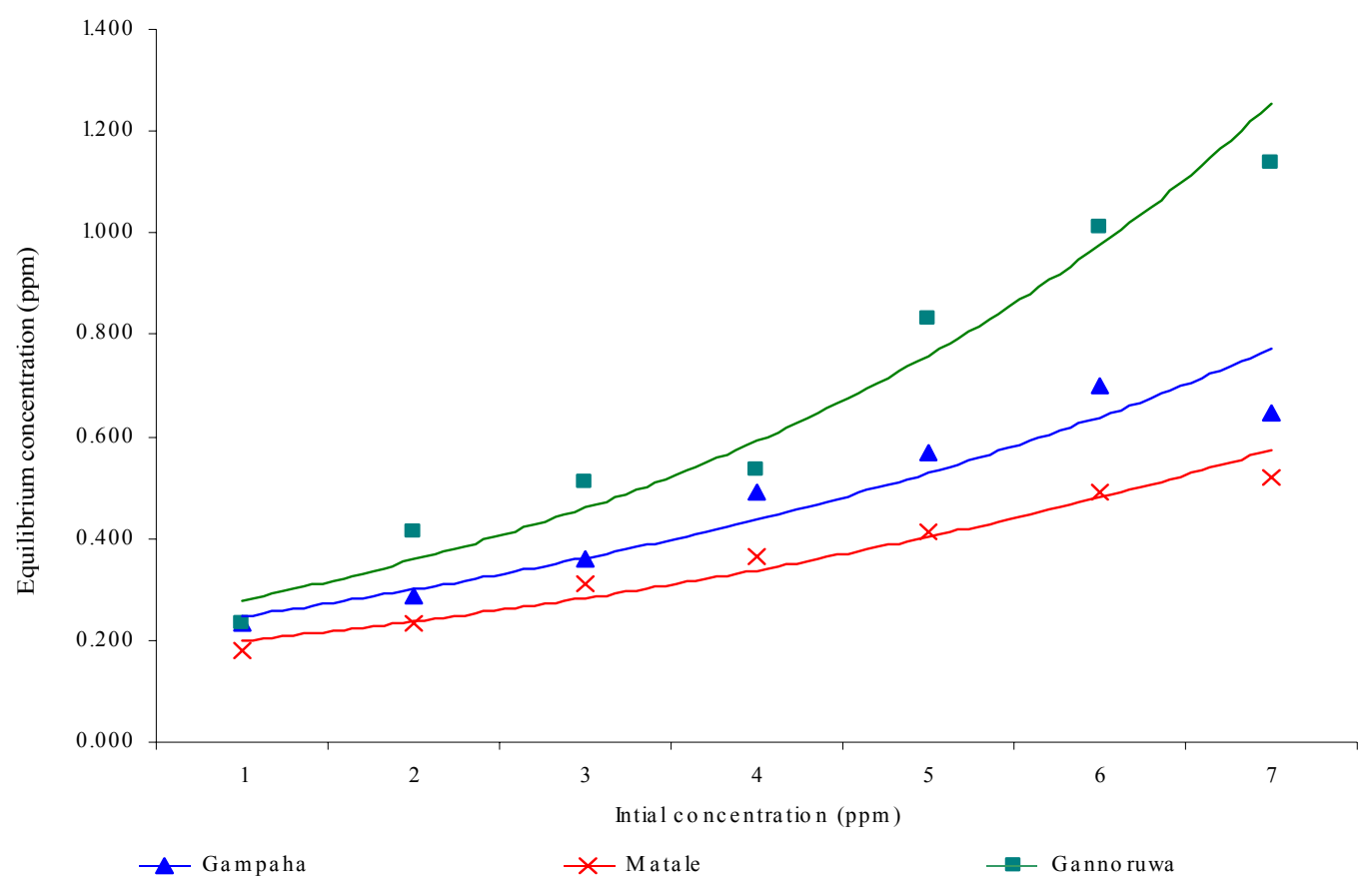

Fig. 2: Thiram concentrations of the water phase after establishment of partition equilibrium of aqueous thiram solutions of different initial concentrations. The standard addition method was used to determine concentrations below the minimum detection limit

concentrations of thiram can be preconcentrated by extracting into $\mathrm{CHCl}_{3}$ as it shows a higher solubility in $\mathrm{CHCl}_{3}$, and that thiram, when present in turbid solutions which cause errornous results in the $\mathrm{UV}$ detection due to scattering, can be extracted into $\mathrm{CHCl}_{3}$ to produce clear solutions. This is of an atmost advantage for the present study to determine thiram in water in contact with soil particles. Determination of thiram in other organic solvents has also been attempted due to similar reasons (Hernandez Olmos et al., 2000).

As thiram is introduced to soil for many reasons, sorption equilibrium of thiram at the soil/water interface would be important to predict the levels of thiram in the environment. The levels would highly depend on the nature of the soil in addition to other conditions such as weather patterns and temperature. The equilibrium concentrations of thiram in the aqueous phase, as determined through solvent extraction into $\mathrm{CHCl}_{3}$ when aqueous thiram solutions of different initial concentrations varying from $1.0 \mathrm{ppm}$ to $10.0 \mathrm{ppm}$ are partitioned with soil (particle of $\mathrm{d}<2 \mathrm{~mm}$ ), are shown in Fig. 2. However, no detectable levels of thiram were found in the aqueous phase at initial concentrations below $3.0 \mathrm{ppm}$. This indicated that adsorption was complete and irreversible when the added amount is less than the capacity of soil. Based on this concentration limit beyond which detectable levels of thiram were obtained in the solution phase, the capacity of soil for thiram was determined to be greater than $6 \mathrm{mg} / \mathrm{kg}$. The capacity would be more for charged adsorbates due to the charge of soil particles (Rytwo et al., 2004).

All three soil types, obtained from different geographical areas of Sri Lanka representing the wet zone (Gannoruwa and Gampaha) and the intermediate wet zone (Matale), showed an increasing trend when the initial concentration was increased. Similar increasing trend was also observed for the thiram content in the soil phase, which was determined by taking the difference between the initial and equilibrium thiram concentrations in the aqueous phase (Fig. 3). Thiram was preferably adsorbed to clay particles and organic matter in soil, and not on sand. Consequently, thiram concentrations were higher in the aqueous phase when partitioned with more sandy soil. Although differences among the three soil types were not 


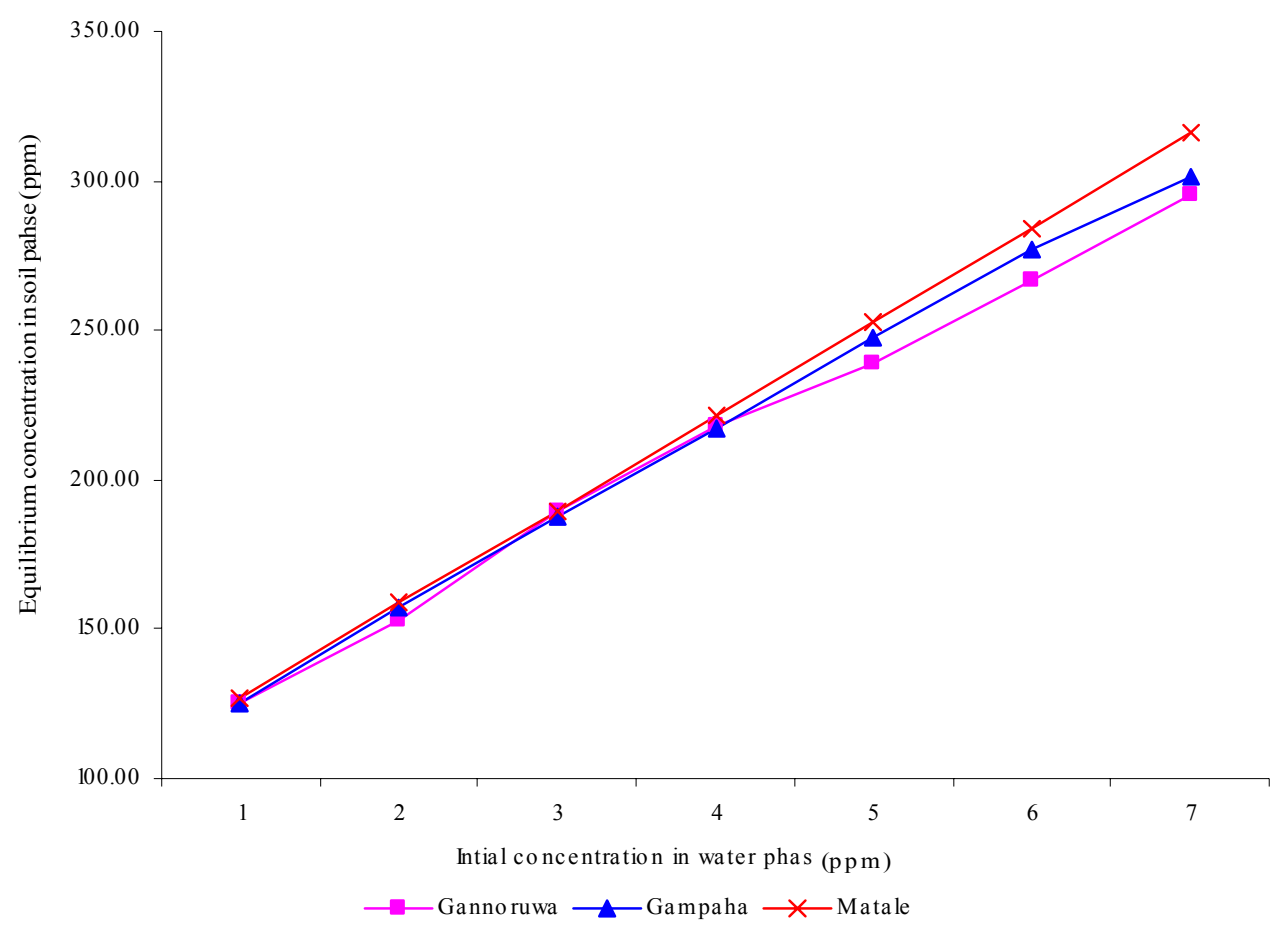

Fig. 3: Average thiram concentrations of the soil phase after establishment of partition equilibrium of aqueous thiram solutions of different initial concentrations

Table 1: Cations present in soil, in ppm, obtained from different areas as determined by atomic absorption spectroscopy

\begin{tabular}{llll}
\hline Cations & Gannoruwa & Gampaha & Matale \\
\hline $\mathrm{Fe}$ & $1.69 \times 10^{5}$ & $7.24 \times 10^{4}$ & $1.92 \times 10^{5}$ \\
$\mathrm{Cu}$ & $<10.0$ & $<10.0$ & $<10.0$ \\
$\mathrm{Zn}$ & $<8.00$ & $<8.00$ & $<8.00$ \\
$\mathrm{Na}$ & $3.66 \times 10^{4}$ & $2.34 \times 10^{4}$ & $3.30 \times 10^{4}$ \\
$\mathrm{~K}$ & $5.46 \times 10^{3}$ & $5.52 \times 10^{3}$ & $5.58 \times 10^{3}$ \\
\hline
\end{tabular}

significant, the small differences observed could be attributed to different cations present in soil (Table 1). Adsorption of thiram on soil containing higher concentrations of cations (e.g., soil from Matale) would be higher due to complex formation ability of thiram.

The reason for not observing a significant difference among the three soil types may be due to the presence of relatively high levels $\mathrm{Cu}$ (II) in all soil types, which readily form a complex with thiram (Zhao et al., 2003). The ratio of the concentration of thiram in the soil to that in the aqueous phase; i.e., the apparent partition coefficient $\left(\mathrm{K}_{\mathrm{D}}{ }^{\prime}\right)$ changed with the initial thiram concentration (Fig. 4), indicating that the rate of increase in the thiram concentration in the aqueous phase and that in the soil phase was not proportional to each other. Further, as there was no detectable thiram in the aqueous phase below $3.0 \mathrm{ppm}$ thiram, the $\mathrm{K}_{\mathrm{D}}{ }^{\prime}$ values at low concentrations would be much higher. This trend was apparent for all three soil types. Although change in $\mathrm{K}_{\mathrm{D}}{ }^{\prime}$ with concentration seemed incorrect when the fundamental aspects of equilibrium systems were concerned, it can be argued that true dynamic equilibrium had not been established at smaller initial concentrations, probably up to $5.0 \mathrm{ppm}$ due to the availability of vacant adsorption sites. Hence, irreversible transfer of thiram molecules from the aqueous phase to the solid phase was probably predominant at such concentrations. Additionally, diffusion of thiram molecules through cavities and pinholes of the soil matrix would probably occur when soil is exposed to thiram solution. However, electrostatic attractions are not possible as thiram is not ionic.

Due to the factors stated above, at low concentrations, the rate of adsorption should be greater than rate of desorption. Upon increasing concentration, thiram molecules would probably be adsorbed on the surface of soil particles and the dynamic equilibrium is 


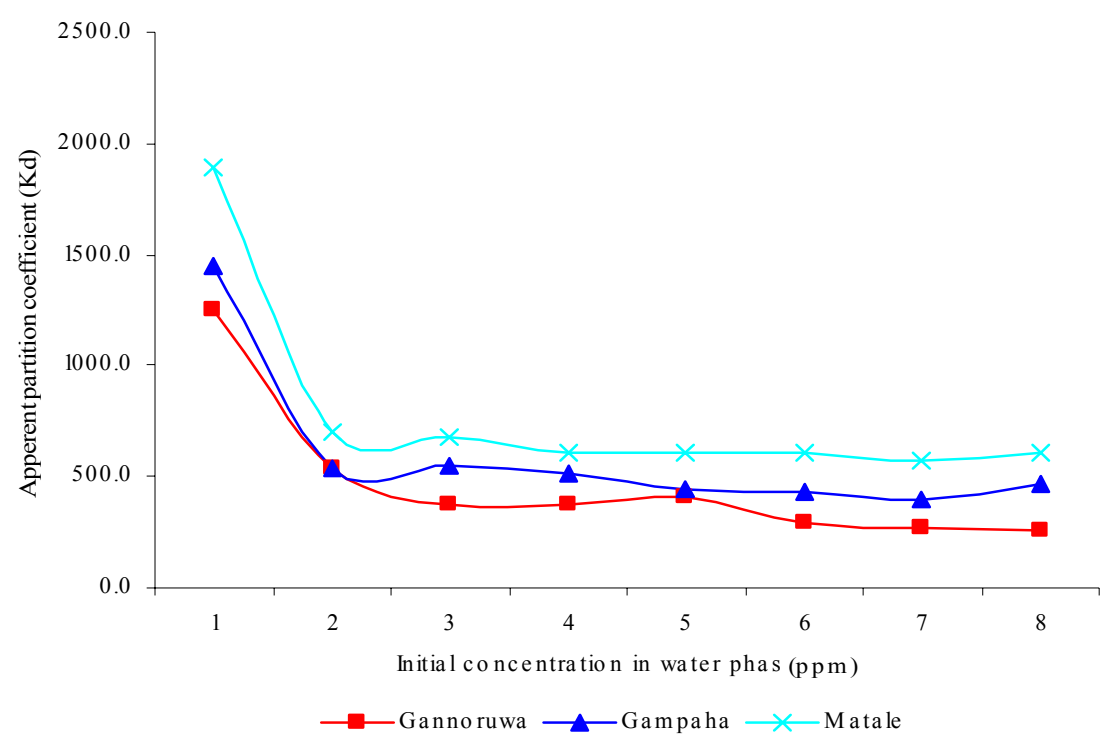

Fig. 4: Variation of apparent partition coefficient $\left(\mathrm{K}_{\mathrm{D}}{ }^{\prime}\right)$ with initial concentration

established, as indicated by the plateau of Fig. 4 after $5.0 \mathrm{ppm}$ thiram concentration. Therefore, the average $\mathrm{K}_{\mathrm{D}}{ }^{\prime}$ value obtained beyond this concentration can be considered as the accurate $\mathrm{K}_{\mathrm{D}}{ }^{\prime}$ representing the distribution of thiram at the soil/water interface. The $\mathrm{K}_{\mathrm{D}}{ }^{\prime}$ value of thiram at the bentonite/water interface was higher probably due to the clay nature of the adsorbent. The average $\mathrm{K}_{\mathrm{D}}{ }^{\prime}$ values obtained for three soil types and for bentonite are given in Table 2 .

As the soil used in this investigation was inhomogeneous in nature, the applicability of the Langmuir isotherm is questionable. Consequently, the validity of the Freundlich isotherm, which is often used to investigate adsorption from liquid solutions, was checked in the present study (Fig. 5).

The correlation coefficient of the least squares lines obtained for the three soil types and the corresponding empirical constants in the isotherm together with associated errors are given in Table 3 .

These constants are statistically not different from each other, indicating that the extent of adsorption of thiram on the selected soil types in Sri Lanka did not have a significant variation.

\section{CONCLUSION}

The simple detection method developed for thiram present in aqueous medium provides excellent analytical characteristics; a minimum detection limit of
Table 2: Average apparent partition coefficient values $\left(\mathrm{K}_{\mathrm{D}}{ }^{\prime}\right)$ for distribution of thiram at the soil/water interface

\begin{tabular}{ll}
\hline Soil type & Average $\mathrm{K}_{\mathrm{D}}{ }^{\prime}$ \\
\hline Gannoruwa & 357 \\
Gampaha & 478 \\
Matale & 629 \\
Bentonite & 5193 \\
\hline
\end{tabular}

Table 3: Empirical constants and correlation coefficient of the Freundlich isotherm

\begin{tabular}{llll}
\hline \multirow{2}{*}{ Soil type } & Correlation & \multicolumn{2}{c}{ Empirical constants } \\
& coefficient & $\mathrm{n}$ & $\mathrm{k}$ \\
\hline Gannoruwa & 0.9982 & 1.08 & 4.69 \\
Gampaha & 0.9995 & 1.04 & 4.59 \\
Matale & 0.9997 & 1.03 & 4.58 \\
\hline
\end{tabular}

$0.170 \mathrm{ppm}$ based on the signal-to-noise ratio of 3 , which is comparable with sophisticated detection methods such as those employed in chromatography, linear dynamic range from $1.00 \mathrm{ppm}$ to $10.0 \mathrm{ppm}$, and a sensitivity of $0.0860 / \mathrm{ppm}$. The average partition coefficient of thiram $\left(\mathrm{K}_{\mathrm{D}}{ }^{\prime}\right)$ between water and $\mathrm{CHCl}_{3}$ phases was determined to be $5.86 \pm 0.54$. The apparent partition coefficient $\left(\mathrm{K}_{\mathrm{D}}{ }^{\prime}\right)$ of thiram between soil, obtained from agricultural fields, and water phases was in the range of 357-629, which increased rapidly at low concentrations. Strong irreversible adsorption of thiram on soil was thus demonstrated. The extent of adsorption on agricultural soil was however lower than that on bentonite, a commercial clay, indicating that 


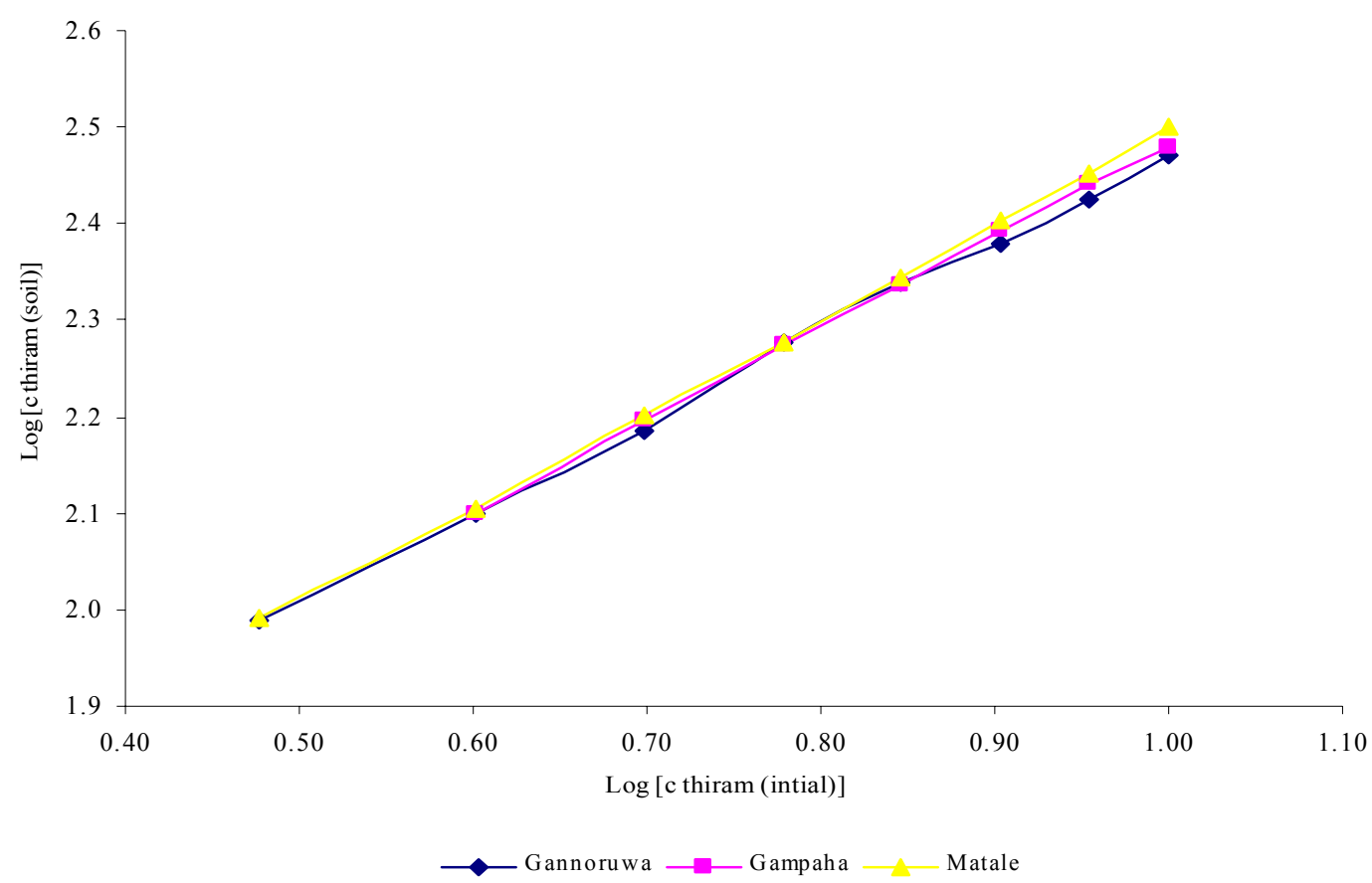

Fig.5: Adsorption analysis for the Freundlich isotherm

thiram was more strongly adsorbed to clay-based materials. Further, there were no major differences among the three soil types with regard to the extent of adsorption of thiram on soil.

Such studies would easily be extended to determine the amount of thiram adsorbed to soil or present in water when thiram is introduced to soil systems for agricultural practices. Adsorption of thiram on soil also indicates the possibility of bioaccumulation through the food chain, if the agricultural run-off water is contaminated with thiram.

\section{ACKNOWLEDGEMENTS}

The authors wish to acknowledge the national science fundation of Sri Lanka for providing a research grant (RG/2005/FR/05) to conduct this project.

\section{REFERENCES}

Akçay, M., (2004). Characterization and determination of the thermodynamic and kinetic properties of p-CP adsorption onto organophilic bentonite from aqueous solution, J. Colloid Interf. Sci., 280 (2), 299-304.

Aulakh, J. S.; Malik, A. K.; Mahajan, R. K., (2005). Solid phase microextraction-high pressure liquid chromatographic determination of nabam, thiram and azamethiphos in water samples with UV detection. preliminary data, Talanta, 66 (1), 266-270.
Boivin, A.; Amellal, S.; Schiavon, M.; Genuchten, M. T., (2005). 2,4-Dichlorophenoxyacetic acid (2,4-D) sorption and degradation dynamics in three agricultural soils, Environ. Pollut., 138 (1), 92-99.

Bradley, C. A.; Halley, S.; Henson, R. A., (2007). Evaluation of fungicide seed treatments on flax cultivars differing in seed color, Ind. Crop. Prod., 25 (3), 301-304.

Ceresera, C.; Bogetb, S.; Parvazc, P.; Revol, A., (2001). An evaluation of thiram toxicity on cultured human skin fibroblasts, Toxicology, 162 (2), 89-101.

Changwen, M.; Yanqing, W.; Chengxing, S.; Leonora, L., (2007). Adsorption characteristics of perchloroethylene in natural sandy materials with low organic carbon content, Environ. Geol., 52 (8), 1511-1519.

Ekroth, S. B.; Ohlin, B.; Osterdahl, B. G., (1998). Rapid and simple method for determination of thiram in fruits and vegetables with high-performance liquid chromatography with ultraviolet detection, J. Agr. Food Chem., 46 (12), 5302-5304.

Fava, L.; Orru, M. A.; Crobe, A.; Caracciolo, A. B.; Botón, P.; Funari, E., (2005). Pesticide metabolites as contaminants of groundwater resources: assessment of the leaching potential of endosulfan sulfate, 2,6-dichlorobenzoic acid, 3,4-dichloroaniline, 2,4-dichlorophenol and 4-chloro-2methylphenol, Microchem. J., 79 (1-2), 207-211.

Fernandez, C.; Reviejo, A. J.; Polo, L. M.; Pingarron, J. M., (1996). HPLC-Electrochemical detection with graphite-poly (tetrafluoroethylene) electrode Determination of the fungicides thiram and disulfiram, Talanta, 43 (8), 1341-1348.

Grosicka, E.; Sadurska, B.; Szumiło, M.; Grzela, T.; Łazarczyk, P.; Niderla-Bielińska, J.; Rahden-Staroń, I., (2005). Effect 
of glutathione depletion on apoptosis induced by thiram in Chinese hamster fibroblasts, Int. J. Immunopharmaco., 5 (13-14), 1945-1956

Han, M. S.; Shin, K. J.; Kim, Y. H.; Kim, S. H.; Lee, T.; Kim, E.; Ryu, S. H.; Suh, P. G., (2004). Thiram and ziram stimulate non-selective cation channel and induce apoptosis in PC12 cells, Neurotoxicology, 24 (3), 425-434.

Herandez-Olmos, M. A.; Agui, L.; Yanez-Sedenaos, P.; Pingarron, J. M., (2000). Analytical voltammetry in lowpermitivity organic solvents using disk and cylindrical microelectrodes. Determination of thiram in ethyl acetate, Electrochim. Acta, 46 (2-3), 289-296.

Kang, J. S.; Hwang, S. Y.; Lee, C. J.; Lee, M. S., (2002). SERS of dithiocarbamate pesticides adsorbed on silver surface; thiram, Bull. Korean Chem. Soc., 23 (11), 1604-1610.

Kaya, A.; Ören, A. H., (2005). Adsorption of zinc from aqueous solutions to bentonite, J. Hazard. Mater., 125 (1-3), 183-189.

Kidd, H.; James, D. R., (1991). The agrochemicals handbook, Royal Society of Chemistry Information Services Cambridge UK, 3, 4-4

Malik, A. K.; Rao, A. L. J., (1990). Spectrophotometric determination of Zineb (a dithiocarbamate fungicide) by the methylene blue method, Talanta, 37 (12), 1205-1207.

Miles, C. J.; Moye, H. A., (1988). Postcolumn photolysis of pesticides for fluorometric determination by highperformance liquid chromatography. Anal. Chem., 60 (3), 220-226.

Onuska, F., (1974). Determination of N,N-dialkyl dithiocarbamates in wastewater by thin-layer densitometry, Anal. Lett., 7 (5), 327-334.

Priyantha, N.; Weliwegamage, S., (2005). Amperometric method for trace level determination of the fungicide, thiram, J. Natl. Sci. Found. Sri Lanka, 33 (1), 17-24.

Priyantha, N.; Weliwegamage, S., (2008). Interaction of thiram with glassy carbon electrode surfaces under applied potentials conditions, Int. J. Electrochem. Sci., 3 (2), 125-135.

Procopio, J. R.; Escribano, M. T. S; Hernandex, L. H., (1988).
Dertermination of thiram in water and soil by cathodic stripping voltammetry based on adsorptive accumulation, Fresen. J. Anal. Chem., 331 (1), 27-29.

$\mathrm{Pu}$, X.; Carlson, G. P.; Lee, L. S., (2003). Oral bioavailability of pentachlorophenol from soils of varying characteristics using a rat model, J. Toxicol. Env. Health A., 66 (21), 20012013

Rytwo, G.; Tropp, D.; Serban, C., (2002). Adsorption of diquat, paraquat and methyl green on sepiolite: experimental results and model calculations, Appl. Clay Sci., 20 (6), 273-282.

Rytwo, G.; Tavasi, M.; Afuta, S.; Nir, S., (2004). Adsorption of difenzoquat on montmorillonite: Model calculations and influence on the hydrophobicity, Appl. Clay Sci., 24 (3-4), 149-157.

Schmidt, T. C.; Zwank, L.; Elsner, M.; Berg, M.; Meckenstock, R. U.; Haderlein, S. B., (2004). Compound-specific stable isotope analysis of organic contaminants in natural environments: a critical review of the state of the art, prospects, and future challenges, Anal. Bioanal. Chem., 378 (2), 1618-2642.

Sharma, V. K.; Aulakh, J. S.; Malik, A. K., (2003). Thiram: degradation, applications and analytical methods, J. Environ. Monitor., 5 (2), 717-723.

Sheng, G.; Yang, Y.; Huang, M.; Yang, K., (2005). Influence of $\mathrm{pH}$ on pesticide sorption by soil containing wheat residuederived char., Environ. Pollut., 134 (3), 457-463.

Spark, K. M.; Swift, R. S., (2002). Effect of soil composition and dissolved organic matter on pesticide sorption., Sci. Total Environ., 298 (1), 147-161.

Tsai, W. T.; Lai, C. W, (2006). Adsorption of herbicide paraquat by clay mineral regenerated from spent bleaching earth., J. Hazard. Mater., 134 (1-3), 144-148.

Zhao, Y. G.; Sheng, X. W.; Huang, Z. Y.; Yang, M. M., (2003). Voltammetric study on the complex of thiramcopper(II) and its applications, Anal. Chim. Acta, 482 (1), 29-36.

\section{AUTHOR (S) BIOSKETCHES}

Priyantha, N., Ph.D., professor in the Department of Chemistry, University of Peradeniya, Sri Lanka. Email: namalpriyantha@pdn.ac.lk

Navaratne, A., Ph.D., senior lecturer in the Department of Chemistry, University of Peradeniya, Sri Lanka. Email: ayanthin@pdn.ac.lk

Ekanayake, C. B. M.Phil., is a research student in the Department of Chemistry, University of Peradeniya, Sri Lanka. Email: ekanayakecb@yahoo.com

Ratnayake, A., B.Sc., is a research student in the Department of Chemistry, University of Peradeniya, Sri Lanka. Email: rathnayakeasanka@yahoo.com

\section{This article should be referenced as follows:}

Priyantha, N.; Navaratne, A.; Ekanayake, C. B. ; Ratnayake, A., (2008). Solvent extraction followed by ultraviolet detection for investigation of tetramethylthiuram disulfide at soil-water interface. Int. J. Environ. Sci. Tech., 5 (4), 547-554. 